\title{
УOBОЗНАВСТВO. NITEPATУРОВНАВСТBO
}

\author{
УДК 82 (560) \\ DOI https://doi.org/10.24919/2308-4863/43-1-15
}

\author{
Ханум Фархад кызы АБДУЛЛАЕВА, \\ orcid.org/0000-0002-7485-9806 \\ научный сотрудник отдела туреикой филологии \\ Института Востоковедения имени академика 3. М. Бунятова \\ Национальной академии наук Азербайджана \\ (Баку, Азербайджан) mehivaqo@mail.ru
}

\section{ОСОБЕННОСТИ ХУДОЖЕСТВЕННОГО СТИЛЯ РОМАНОВ ГУСЕЙНА РАХМИ ГЮРПЫНАРА}

\begin{abstract}
Начало литературной деятельности Гусейна Рахми Гюрпынара совпало со временем великих перемен в Туричии. Одной из отличительных черт его произведений было то, что он разоблачал нелепые традиции, суеверия и невежественные убеждения различных слоев общества, иногда на фоне реальных, а иногда и воображаемых событий. Писатель родился в Стамбуле в 1864 году, жил и работал в этом городе до кониа своей жизни. Гусейн Рахми - один из тех редких людей, кто обладал высокой культурой и интеллектом. В своих произведениях писатель не изображал людей и события на фоне грустных или тяжельх сочииальных проблем. В романах Гусейна Рахми изображение жизни людей служсло главным образом поводом для развлечения. Это было также связано с образом жизни общества, в котором писатель вырос. Такой подход писателя, который высмеивал практически все, с чем сталкивался, и легко мог подмечать забавную сторону в каждом событии и каждой истории, напомнил читателю Гарагеза, героя знаменитой народной пьесы. Такое отнотение не только не удручало его, но и повышило его интерес к своей личности и творчеству. Хусейн Рахми пробовал свои силь в написании многих романов, рассказов, пьес и критических стихотворных жанров. Он выстуупал в роли духовного преемника А. Мидхата Эфенди, причем больше основываясь на конщепџии своего учителя «писать романь для народа».

Мы можем изучать романы автора по трем основным направлениям. Влияние романтизма больше прослеживается в ранних романтических произведениях. Поворотным моментом в творчестве Г. Рахми можно считать роман «Мураббийа», написанный в 1899 году. После этого романа реалистично-натуралистическое направление в его творчестве стало более заметным. В последние годы своей карьеры он писал больше психологических романов. Однако на протяжении всей своей творческой деятельности он оставался верным романтизму.
\end{abstract}

Ключевые слова: турецккая литература ХІХ века, проза, жанр романа, сатирический стиль, Гусейн Рахми Гюрпьнар, «Мураббийя».

Ханум Фархад АБДУЛЛАСВА, orcid.org/0000-0002-7485-9806

науковий співробітник відділу туреиької філологіі Інституту Сходознавства імені академіка 3. М. Бунятова Національної академії наук Азербайджану (Баку, Азербайджан) mehivaqo@mail.ru

\section{ОСОБЛИВОСТІ ХУДОЖНЬОГО СТИЛЮ РОМАНІВ ГУСЕЙНА РАХМІ ГЮРПИНАРА}

Початок літературної діяльності Гусейна Рахмі Гюрпінара збігся із часом великих змін у Туреччині. Однією 3 відмітних рис його творів було те, щзо він викривав безглузді традииії, забобони та неосвіченість різних верств суспільства, іноді на тлі реальних, а іноді й уявних подій. Письменник народився у Стамбулі в 1864 роиі, жив $i$ праиюввв у изьому місті до кіния свого життя. Гусейн Рахмі - один із тих рідкісних людей, хто володів високою культурою й інтелектом. У своїх творах письменник не зображував людей та події на тлі сумних чи важких соиіальних проблем. У романах Гусейна Рахмі зображення життя людей було головним чином приводом для розваги. Це також було пов'язано зі способом жсттяя суспільства, у якому письменник виріс. Такий підхід письменника, який висміював практично все, із чим стикався, і легко міг помічати кумедний бік у кожній події та кожній історії, нагадав читачеві Гарагеза, героя відомої народної n'єси. Таке ставлення не тільки не пригнічувало його, а й підвищувало його інтерес до своєї особистості та творчості. Хусейн Рахмі пробував свої сили в написанні багатьох романів, оповідань, n'єс та критичних віриованих жанрів. Він виступав у ролі духовного наступника A. Мідхата Ефенді, причому грунтуючись на концепції свого вчителя «писати романи для народу». 
Ми можемо вивчати романи автора за трьома основними напрямами. Вплив романтизму більше простежується в ранніх романтичних творах. Поворотним моментом у творчості Г. Рахмі вважається роман «Мураббія», написаний у 1899 роиі. Після изього роману реалістично-натуралістичний напрям у його творчості став помітнішим. Останніми роками своєї кар 'єри він писав більше психологічних романів. Однак протягом усієї своєї творчої діяльності він залишався вірним романтизму.

Ключові слова: турецька література ХІХ столітmя, проза, жанр роману, сатиричний стиль, Гусейн Рахмі Гюрпінар, «Мураббія».

\author{
Khanum Farhad ABDULLAEVA, \\ orcid.org/0000-0002-7485-9806 \\ Researcher at the Department of Turkish Philology \\ Institute of Oriental Studies named after Acad. \\ Z. M. Bunyatova of the National Academy of Sciences of Azerbaijan \\ (Baku, Azerbaijan)mehivaqo@mail.ru
}

\title{
FEATURES OF THE ARTISTIC STYLE OF THE NOVELS OF HUSEYN RAHMI GYURPYNAR
}

The beginning of Husein Rahmi Gyurpinar's literary activity coincided with the time of great changes in Turkey. One of the hallmarks of his writings was that he exposed the ridiculous traditions, superstitious beliefs and ignorant beliefs of various sectors of society, sometimes against the backdrop of real and sometimes imaginary events. The writer was born in Istanbul in 1864 and lived and worked in this city for the rest of his life. Huseyn Rahmi is one of those rare people who possessed high culture and intelligence. In his works, the writer did not depict people and events against the background of sad or difficult social problems. In Hussein Rahmi's novels, portrayal of people's lives was mainly an occasion for entertainment. It was also related to the lifestyle of the society in which the writer grew up. This approach of the writer, who ridiculed almost everything he came across, and could easily notice the funny side in every event and every story, reminded the reader of Garagez, the hero of the famous folk play. Such an attitude not only did not depress him, but also increased his interest in his personality and work. Hussein Rahmi tried his hand at writing many novels, short stories, plays and critical poetry genres. He acted as the spiritual successor of A. Midhat Efendi, moreover, based more on the concept of his teacher "to write novels for the people".

We can study the author's novels in three main directions. The influence of romanticism can be traced more in the early romantic works. The novel "Murabbiya", written in 1899, can be considered a turning point in the work of G. Rahmi. After this novel, the realistic-naturalistic direction in his work became more noticeable. In the last years of his career, he wrote more psychological novels. However, throughout his entire creative career, he remained faithful to romanticism.

Key words: Turkish literature of 19'th century, prose, novel genre, satirical style, Huseyn Rahmi Gyurpinar, "Murabbiya".

Начало литературной деятельности Хусейна Рахми Гюрпынара совпало с началом великой реформации в Турции. Одной из отличительных черт его произведений было преувеличенное изображение всех слоев общества, переживавшего коренные изменения, иногда на фоне реальных, а иногда и воображаемых событий, в основном нелепых традиций, обычаев и невежественных верований. Писатель родился в Стамбуле в 1864 г., жил и работал в этом городе до конца своей жизни. Х. Рахми, потерявший мать в раннем возрасте, вырос также и вдали от отца, который постоянно был в разъездах из-за своей работы. Его обучением и воспитанием занималась бабушка по матери. Из-за болезни он бросил школу «Мулькийя», куда был принят для продолжения образования. Как и большинство молодых людей своего времени, он постоянно работал над собой и совершенствовал свой французский язык.

Гусейн Рахми рано начал писать, работал в различных сферах, и, хотя он два срока подряд избирался членом парламента, он нашел себя в литературе, а через некоторое время полностью увлекся писательством. Писатель умер в Стамбуле в 1944 г., был похоронен там же, на кладбище Аббас-паши.

Гусейн Рахми был одной из немногих личностей, обладавших высокой культурой и интеллектом. Хотя он вырос в семье богатого государственного служащего, он всегда был привязан к людям, глубоко интересовался их проблемами. Люди, их быт, обычаи и традиции - главная тема романов писателя на полусерьезном, полусатирическом языке. Хотя в обществе, в котором он вырос, между людьми существовали глубокие социальные различия, он сумел уловить золотую середину, сердцем и разумом он не был одним из них, но всегда мог уловить их чувства и пожелания (Kabakl1, 2008: 296).

В своих произведениях писатель не работал над представлением о людях как изнуренных и подавленных, или на фоне каких-то глубоких 
социальных проблем. Изображение народной жизни развивалось в романах Гусейна Рахми главным образом в развлекательном плане. Это было также связано с образом жизни общества, в котором писатель вырос. Такой подход писателя, который высмеивал практически все, что встречал, и легко мог видеть забавную сторону в каждом событии и рассказе, напоминал читателю героя известной народной пьесы Гарагёза. Такой подход не только не злил людей, но и повышал их интерес к личности и творчеству самого писателя. Когда мы знакомимся с его произведениями, мы видим, что, как и большинство писателей того времени, он был не только профессионалом в определенной области, но и всесторонним знатоком многих других областей жизни. Как и его современники, он в основном интересовался французской литературой и прессой. Он приложил много усилий для формирования турецкой литературы, во многом перенимавшей стиль и жанровое своеобразие западной литературы. Исследователь Рафик Ахмед Севангиль в своих воспоминаниях о писателе отмечает: «<... Несмотря на возраст, он всегда был динамичен и полон жизни. Он, будучи веселым человеком, всегда искал в жизни интересные темы и живые мысли. У него это довольно легко получалось. Он описывает все вокруг себя, далекое и близкое, причем вежливо, как говорится, никого «не подминая» под себя, интеллигентно, с тонким чувством юмора. Он любит побеждать и любит людей, он умеет их критиковать, но он всегда избегает властности и в целом был довольно застенчивым. Он не очень доверял людям, потому что боялся быть обманутым. Выпады против общества, против среды, казалось, успокаивали его. Может быть, поэтому он был так счастлив, когда написал роман «Безумный философ». Время от времени объектом критического смеха становились не только окружающие, но и он сам < ..>» (Sevengil, 1944: 11).

Гусейн Рахми пробовал свои силы в написании романов, рассказов, пьес и критических стихов. Тридцать шесть из пятидесяти четырех произведений автора - романы, семь - большие рассказы (Kabakl1, 2008: 298). Самыми известными из его романов являются «Шик» (1889 г.), «Мураббийа» (1899 г.), «Шыпсевди» (1911 г.), «Женитьба под кометой» (1912 г.), «Гульябани» («Снежный человек») (1912 г.), «Радость в доме, или как взбаламутилась свекровь» (1922 г.), «Я - придурок?» (1925 г.) и другие (Gürsel, 2000).

Несмотря на то, что он писал и творил в период литературного направления «Сарвати-фюнун», Г. Рахми, как и другие представители среднего поколения, писал произведения в другом стиле мышления, направлении и методе. Он действовал как духовный преемник А. Мидхата Эфенди, больше полагаясь на концепцию своего учителя «писать романы для народа». Нельзя сказать, что Г. Рахми был представителем какого-либо прозападного литературного движения. Этот аспект присутствовал и в творчестве мастера А. Мидхата.

Можно изучать романы автора по трем основным направлениям. Влияние романтизма больше прослеживается в ранних римских экспериментах. Поворотным моментом в творчестве Х. Рахми можно считать роман «Мураббийа» 1899 г. После этого романа реалистическо-натуралистическое направление в его творчестве становится более заметным. В последние годы своей карьеры он писал больше психологических романов. Однако на протяжении всей карьеры он оставался верным романтизму. Как видно, писатель обратился практически ко всем типам жанров романа. Сам Г. Рахми писал об этом как в критико-публицистических произведениях, так и в своих романах: « $<$..> С начала применения натурализма и экспериментализма в нашей литературе подход к ней изменился. Следуя новой литературной традиции, мы стараемся изображать персонажей, которых будем играть в наших романах, сначала в образе их родителей и семьи, а затем на фоне изменений в их личностях под влиянием окружающей среды и общества. Таким образом, мы описываем приключения человека, который вырос в определенных условиях и жил в определенной социальной среде, в соответствии с природными обстоятельствами» (Korkmaz, 2007: 112).

Такие сюжеты и стиль раскрытия проблемы в его романах не всегда признавались в обществе. Защищая свой роман «Я что, сошел с ума?», из-за которого его обвиняли в аморальности и передали дело в суд, автор сказал следующее: «Сегодня писать роман в соответствии с требованиями реализма и натурализма - значит иметь глубокие научные познания. Изображая солнце, воздух, общество, моральные ценности и традиции, короче говоря, со всеми деталями, вы создадите полуюмористическую среду. Затем вы, войдя в образ своего героя, который может быть представлен самыми разными социальными слоями населения, стремитесь воплотить их в жизнь в определенной истории в виде нечестных, образованных, необразованных, угнетенных, жестоких и злых личностей. Вы коснетесь массы различных социальных проблем и душевных ран, которые они открывают. Вы вместе с врачом будете обращаться к знахарям, вы отправитесь в морг. Вы решительно будете двигаться по пути истины и ничего не скроете от людей» (Engünün, 1991). 
Подобное отношение к собственному творчеству было также связано с характером Г. Рахми. Хотя в его работах наблюдались романтический, эмоциональный и юмористический стили, наблюдательно-выжидательный метод, который был основной линией реализма, им всегда использовался параллельно. Стремление открыто описывать безобразия общественной жизни привело писателя к своего рода натурализму. Г. Рахми, прежде всего, ощущал себя журналистом. По дороге или же пребывая где-либо, он записывал все, что привлекало его внимание и стимулировало к дальнейшему творчеству. Конечно, главная особенность творчества Г. Рахми - развлекаться, видя карикатурную сторону жизни, раскрывать сатирическую сторону простейших событий, превращать их в мишень для смеха. Читая его романы, мы видим, что они затрагивают наиболее злободневные темы. Он описывал все недостатки социальной среды без всяких оправданий, открыто разоблачая ее. Он основал свое заявление на идее о том, что люди должны признавать свои ошибки и грехи, чтобы в дальнейшем избегать их. Литература отражает жизнь, а в жизни происходит как прекрасное, так и безобразное.

Романы Г. Рахми просты по сравнению с романами современных ему писателей. Основной целью написания романа, как и у его учителя А. Мидхата, был расчет на широкий круг читателей. В основном он писал романы для публикации их в прессе. Писатель, который обеспечивал себе материальный доход своим пером, иногда делал неподходящие длинноты «ради письма», а также писал романы на определенную тематику. Основная сюжетная линия его романов делилась на второстепенные и третьестепенные вспомогательные сюжеты, в итоге он сильно отходил от основной темы произведения. На первый взгляд тема, ход событий, выбор героев и некоторые веселые заметки, добавленные к произведению, делали эти романы удобочитаемыми (Köprülü, 1986). Однако использование комических моментов на протяжении всего произведения уводило жанр романа, нацеленного на интеграцию в западную литературу, от его первоначальной цели, делало повествование похожим на традиционное повествование в народных постановках. Те забавные моменты, которые привлекали внимание читателя, одновременно отвлекали его от основной идеи произведения. В итоге складывалось впечатление, будто читатель знакомился со смешным длинным анекдотом, не понимая сути произведения. Однако этот аспект, который никогда не присутствовал у А. Мидхата и казался очень про- стым представителям литературной школы «Сарвати-фунуна», на самом деле был преимуществом творчества Г. Рахми (Kabakl1, 2008: 300). Точнее было бы сказать, что он на местном языке писал не народные романы, а комедии.

Еще одной особенностью его романов было то, что он, резко прерывая повествование, излагал какие-либо философские или энциклопедические сведения. Если А. Мидхат Эфенди давал эту информацию по-своему, то Г. Рахми непосредственно разговаривал со своими героями. Например, в романе «Шыпсевди» способы поедания алафранги подробно объясняются от лица героевпредставителей «философии детерминизма». Примером тому могут послужить споры невежественных женщин о поэзии и философии, высказывания арабских детей о композиторе Ф. Шопене, мнение уличной молодежи о новой литературе. Писатель считал, что таким образом было бы эффективнее пробудить интерес людей к инновациям и европейской культуре. То есть это не было просто сухими философскими рассуждениями. Это нужно было излагать по отдельности в произведениях искусства. По этой причине он и привык размещать в романах научно-философские и социологические идеи и рассуждения (Moran, 2013). Этот метод позволил на первых порах нововведению быстрее распространяться среди масс.

Что касается тем, затронутых в романах Г. Рахми, то мы видим, что они основаны на жизненных событиях, которые автор непосредственно видел, слышал или о которых читал в газетах. Добавляя собственное видение реальных событий, писатель расширял и переделывал эти темы на основе творческого воображения. Как он сам отмечал, тема романа «Мураббийа» взята из жизни семьи его соседа Ахмада Вефика-паши. Дахри-паша в романе - художественный прообраз А. Вефик-паши. Или ночь, которую он провел в казино Ени Пандик, которое он описывает в своем романе «Дамы в казино», где изображены женщины с вызывающим поведением, которых он встречал в реальной жизни.

Темы, над которыми он работал в своих романах, всегда были актуальными. Например, роман «Брак под кометой» был вдохновлен слухами о том, что комета Галлея пройдет близко к Земле и разрушит мир. «Колдовство» - это роман об эпидемии алкоголизма, которая была в моде в то время.

Г. Рахми писал свои романы, чтобы передать, внушить конкретную идею. Основная же идея, которую он хотел донести, была основана на построении определенной сюжетной линии в соответствии с ней. Подавляющее большинство его романов - это 
романы, понятные самым простым жителям Стамбула. Г. Рахми после А. Мидхат Эфенди - самый профессиональный писатель, который широко выражал интересы людей, их традиции, проблемы и недостатки в современном понимании. Он вновь и вновь показывал кровоточащие раны общества, такие, как подражание, бедность, суеверия, внебрачные дети, погоня за наследством, развод и лихоимство, что является показателем его упорной работы в этом направлении.

Атмосфера Стамбула, претерпевшая существенные изменения при его жизни, дома и кварталы, которых уже нет в наше время, с особым тщанием сохранены в романах Г. Рахми. Традиции Рамадана, принц, путешествия, набеги на окрестности, конные трамваи, соседские женщины, траурные церемонии, богатые особняки наследников и наложниц, гадалок, ведьм, бакалейщиков оживают, как фотоальбом. Одежда, речь и образ мышления всех представителей стамбульского населения, особенно бедных и невежественных, слуг, наложниц, акушерок, возниц и бездомных отражали образ жизни того времени как в документальном фильме.

Этот стиль, который он использовал в своих романах, иногда производил впечатление некоторого повторения образов его героев. Этот выбор персонажей также основан на методе выбора предмета. Основная цель заключалась в том, чтобы доказать читателю свою объективность, возродив некоего персонажа с отрицательными качествами (Korkmaz, 2007). Хотя эти изображения взяты из реальной жизни, очевидно, что они также дополнены развитым писательским воображением. Писатель безжалостно развенчивает эти негативные типы. Чтобы сделать образы более реальными, он раскрывает все уродство своих героев во всей их наготе. Можно сказать, что положительных героев очень мало.

Понятие времени также актуально в романах Г. Рахми. То есть события, описанные в произведении, относятся к тому периоду, в котором жил писатель. Будучи свидетелем самого бурного исторического периода в Турции, писатель сумел воссоздать этот период, используя его, как исторический источник.

Романы написаны беглым языком и стилем, легко воспринимаются. Стамбульский диалект - ведущий язык у писателя. Каждый из героев говорит на своем диалекте. Он даже добавил роману естественности и живости, наделяя своих нетурецких героев забавными способами говорить, странными словами и выражениями. Двенадцать его романов начались с речей сплетниц из соседских кварталов
(Kabakl1, 2008: 303). В то же время Г. Рахми, ограничив ведущий, основной для своих романов сюжет, в своих научных и философских выступлениях склонялся к довольно строгому языку и стилю. То есть он создавал романы необычным способом, который не был похож на старый или новый, и стремился извлекать пользу из того и другого.

Писатель, основной целью которого при написании романа было просвещение народа, пробовал все способы, которые он считал нужными. Он написал поучительные и забавные романы, понятные широкому кругу людей, у этих романов есть собственный язык, тема, близкие этим людям герои.

Первым романом, принесшим большую известность Г. Рахми, был «Мураббийа». Основная тема здесь - негативные аспекты иностранного воспитания детей, ставшего модным в то время в богатых семьях, и обнажение реальных сторон характера женщин из Европы, приезжавших сюда во имя этой работы. Роман решительно осуждает лицемерные семейные отношения. Автор напоминает нам, что, когда няне доверяют детей, мы должны более тщательно ее подбирать. Приход домой няни должен быть шагом к будущему ребенка, а не для того, чтобы показать обществу свой статус. С другой стороны, в богатых семьях подчеркивается асоциальное поведение и аморальность. Роман впервые был опубликован в газете «Икдам» (Gürpınar, 2021: 3). Позже она была издана в виде книги в Икдамской типографии.

В свои 65 лет Дахри Эфенди был настоящим тираном. Чтобы уменьшить влияние на воспитанника извне, он, в соответствии с социальными принципами того времени, приводит в свое поместье западную няню по имени Анжелика. У Анжелики было темное и асоциальное прошлое. Анжелика, будучи аморальной, начала вступать в интимные отношения со всеми мужчинами в доме. В нее были влюблены все, включая самого Дахри Эфенди, то есть его сын Шами, брат Амджабек и зять Садри. Эти трое влюбленных, совершенно не сомневающиеся в невинности Дахри Эфенди, начинают ревновать к ней друг друга. Дахри Эфенди запрещает Шами и Амджабеку посещать особняк. Шами, потерявший право входа в дом, просто стал терять разум от мысли, что у няни отношения с Садри, он ревнует и не знает, что делать. При поисках он с ужасом замечает, что в шкафу Анжелики прячется не Садри, а Дахри Эфенди. Этот момент является кульминацией событий. Анжелика очень испугалась, когда разгневанный Садри внезапно вошел в комнату с кинжалом в руке. Он не предполагала, что та любовная игра, которую она разыграла с тремя мужчинами, закончится так 
плачевно. Шами ворвался в комнату, как сумасшедший, открывая подряд шкафы, осматриваясь и все время спрашивая девушку, где же негодяй, пока не обнаружил этого «врага», которого искал. Девушка плакала, говоря, что никого нет. Когда он потребовал ключ от последнего шкафчика, она отдает его ему. Когда Шами подошел к шкафу и открыл его, то закричал от неожиданности и волнения: «Шами поднял кинжал одной рукой, чтобы убить своего врага с первой же попытки, не дав ему убежать. Он стоял в готовом для удара положении. Когда же он открыл шкаф свободной рукой, то отступил на два шага назад в изумлении от того, что увидел:

- Ох <..> эфенди отец! <..>

Испустив крик, он отбросил кинжал в одну сторону, а сам рухнул в другую сторону. Вот такие дела < ..> Отец Шами, уважаемый эфенди, вышел из гардероба Анжелики, белобородый и с покрасневшим лицом. Он сделал несколько шагов к середине комнаты. Он взглянул на двух молодых людей, распростертых на полу в обморочном состоянии. И он стал третьим, упавшим в обморок <..>» (Gürpınar, 2021: 215-216).

Выводы. Изучая жизнь и творчество Гусейна Рахми Гурпинара, одного из ярчайших представителей турецкой литературы среднего поколения, можно прийти к выводу о его важной роли в становлении и развитии современной турецкой литературы. Писатель, не состоявший ни в каком литературном сообществе или движении своего времени, создавал интересные, а главное, высокохудожественные литературные произведения.

\section{СПИСОК ИСПОЛЬЗОВАННЫХ ИСТОЧНИКОВ}

1. Kabaklı Ahmet. Türk Edebiyatı. Türk Edebiyatı Vakfı Yay. III s. İstanbul, 2008. 847 s.

2. Sevengil Ahmet Refik. Hüseyn Rahmi Gürpınar. İstanbul : Hilmi Kitabevi, 1944. 163 s.

3. Gürpınar Hüseyin Rahmi. Mürebbiye. Haz. : Ayşe Şeker. İstanbul : TDK Yay., 2021, 216 s.

4. Korkmaz Ramazan. Yeni Türk Edebiyat1. Ankara : Grafiker Yay., 2007. 608 s.

5. Engünün İ. Yeni Türk Edebiyatı Araştırmaları. İstanbul : Dergah Yay., 1991. 670 s.

6. Gürsel A. Çağdaș Türk Romanı Üzerine İncelemeler. İstanbul : Doğu Batı Yayınları, 2000. 480 s.

7. Korkmaz R. Yeni Türk Edebiyatı. Ankara : Grafikler Yayıncılık, 2007. 608 s.

8. Köprülü M. F. Türk Edebiyatı Tarihi. Istanbul : Ötüken Yay., 1986, XXIV + 437 s.

9. Moran B. Türk Romanına Eleştirel Bir Bakış. Istanbul : İletişim Yay., 2015. 336 s.

\section{REFERENCES}

1. Ahmet Kabaklı. Türk Edebiyatı [Turkish literature]. Türk Edebiyatı Vakfi Yay., III s., İstanbul, 2008. 847 s. [in Turkish].

2. Ahmet Refik Sevengil. Hüseyn Rahmi Gürpınar [Huseyn Rahmi Gurpinar]. Hilmi Kitabevi, İstanbul, 1944.163 s. [in Turkish].

3. Hüseyin Rahmi Gürpınar. Mürebbiye [Governess]. Haz. : Ayşe Şeker. TDK Yay., İstanbul, 2021. 216 s. [in Turkish].

4. Ramazan Korkmaz. Yeni Türk Edebiyatı [New Turkish Literature]. Grafiker Yay., Ankara, 2007. 608 s. [in Turkish].

5. Engünün İ. Yeni Türk Edebiyatı Araştırmaları [New Turkish Literature Studies]. İstanbul : Dergah Yay., 1991. 670 s. [in Turkish].

6. Gürsel A. Çağdaş Türk Romanı Üzerine İncelemeler [Reviews on Contemporary Turkish Novel]. İstanbul : Doğu Batı Yayınları, 2000. 480 s. [in Turkish].

7. Korkmaz R. Yeni Türk Edebiyatı [New Turkish Literature]. Ankara: Grafikler Yayıncılık, 2007, 608 s. [in Turkish].

8. Köprülü M. F. Türk Edebiyatı Tarihi [History of Turkish Literature]. Istanbul: Ötüken Yay., 1986, XXIV + 437 s. [in Turkish].

9. Moran B. Türk Romanına Eleştirel Bir Bakış [A Critical Look at Turkish Novel]. Istanbul: İletişim Yay., 2015,336 s. [in Turkish]. 